\title{
Regulation of Class $A \beta$-Lactamase CzoA by CzoR and IscR in Comamonas testosteroni S44
}

\author{
Weiping Zhuang ${ }^{1 \dagger}$, Hongliang Liu'${ }^{2 \dagger}$, Jingxin $\mathrm{Li}^{1}$, Lu Chen ${ }^{1}$ and Gejiao Wang ${ }^{1 *}$ \\ 'State Key Laboratory of Agricultural Microbiology, College of Life Science and Technology, Huazhong Agricultural \\ University, Wuhan, China, ${ }^{2}$ Shandong Provincial Research Center for Bioinformatic Engineering and Technique, School of \\ Life Sciences, Shandong University of Technology, Zibo, China
}

A genomic analysis of Comamonas testosteroni S44 revealed a gene that encodes a LysR family transcriptional regulator (here named $c z o R$, $\underline{\mathrm{czo}}$ for $\underline{\text { cefazolin) located }}$ upstream of a putative class A $\beta$-lactamase encoding gene (here named $c z O A$ ). A putative DNA-binding motif of the Fe-S cluster assembly regulator IscR was identified in the $C Z O R-C Z O A$ intergenic region. Real-time RT-PCR and lacZ fusion expression assays indicated that transcription of $C z O A$ and $C z O R$ were induced by multiple $\beta$-lactams. CzoA expressed in Escherichia coli was shown to contribute to susceptibility

OPEN ACCESS

Edited by:

Xian-Zhi Li,

Health Canada, Canada

Reviewed by:

Zhiyong Zong,

West China Hospital, China

Yuji Morita,

Aichi Gakuin University, Japan

*Correspondence:

Gejiao Wang

gejiao@mail.hzau.edu.cn

tThese authors have contributed equally to this work.

Specialty section: This article was submitted to Antimicrobials, Resistance and Chemotherapy,

a section of the journal

Frontiers in Microbiology

Received: 12 August 2017 Accepted: 11 December 2017 Published: 22 December 2017

Citation:

Zhuang W, Liu H, Li J, Chen L and Wang $G$ (2017) Regulation of Class

A $\beta$-Lactamase CzoA by CzoR

and IscR in Comamonas testosteroni

S44. Front. Microbiol. 8:2573.

doi: 10.3389/fmicb.2017.02573 to a wide range of $\beta$-lactams judged from minimum inhibitory concentrations. In vitro enzymatic assays showed that CzoA hydrolyzed seven $\beta$-lactams, including benzylpenicillin, ampicillin, cefalexin, cefazolin, cefuroxime, ceftriaxone, and cefepime. Deletion of either iscR or $c z O R$ increased susceptibility to cefalexin and cefazolin, while complemented strains restored their wild-type susceptibility levels. Electrophoretic mobility shift assays (EMSA) demonstrated that CzoR and IscR bind to different sites of the $C z O R-C z O A$ intergenic region. Precise CzoR- and IscR-binding sites were confirmed via DNase I footprinting or short fragment EMSA. When cefalexin or cefazolin was added to cultures, $c z o R$ deletion completely inhibited $c z O A$ expression but did not affect isc $R$ transcription, while iscR deletion decreased the expressions of both $C Z O R$ and $C Z O A$. These results reveal that CzoR positively affects the expression of $c z O A$ with its own expression upregulated by IscR.

Keywords: Comamonas testosteroni, CzoR, IscR, cephalosporin resistance, Class A $\beta$-lactamase

\section{INTRODUCTION}

$\beta$-Lactam antibiotics are currently one of the most widely used antibacterial classes to treat infectious diseases, with cephalosporins (e.g., cefalexin, cefazolin, and cefradine) accounting for nearly half of all $\beta$-lactam antibiotic prescriptions (Bush and Bradford, 2016). Resistance of pathogenic bacteria to $\beta$-lactams has led to antibiotic treatment failures (Bush, 2013). Moreover, a number of environmental isolates have also shown a highly intrinsic or adaptive resistance to antibiotics. Production of $\beta$-lactamases is the primary mechanism of $\beta$-lactam resistance (Giwercman et al., 1992; Bush, 2013). Based on amino acid sequences, $\beta$-lactamases have been classified into four molecular classes. Classes $\mathrm{A}, \mathrm{C}$, and $\mathrm{D} \beta$-lactamases hydrolyze their substrates through an active site serine, whereas Class $B \quad \beta$-lactamases are metalloenzymes that require divalent zinc ions for their activities (Walsh et al., 2005). 
A large number of $\beta$-lactamases have been reported, among which the Class A enzymes are the most abundant (Bush and Jacoby, 2010). The substrates of these class A $\beta$-lactamases are mostly penicillins, monobactams, early cephalosporins, and extended-spectrum cephalosporins, and these enzymes are inhibited by $\beta$-lactamase inhibitors, such as clavulanic acid, tazobactam, and sulbactam (Bush and Jacoby, 2010). Diverse class A $\beta$-lactamases have been studied for various genera, including GIL-1 from Citrobacter gillenii, AST-1 from Nocardia asteroids, PenA from Burkholderia cepacia, NmcA from Enterobacter cloacae, CumA from Proteus vulgaris, SmeA from Serratia marcescens, CdiA from Citrobacter diversus, Sed-1 from Citrobacter sedlakii, HugA from Proteus penneri, and BlaA from Yersinia enterocolitica (see review of Philippon et al., 2016).

Underlying regulatory mechanisms of $\beta$-lactamases have been largely focused on the class $C \beta$-lactamase AmpC, which is regulated by the LysR family transcriptional AmpRs regulator of Citrobacter freundii and E. cloacae (Lindquist et al., 1989; Guérin et al., 2015). In the presence of $\beta$-lactams, an excessive breakdown of murein leads to the accumulation of AmpD-unprocessed muramyl peptides presumably, but not $\beta$-lactam itself, binding AmpR, which induces a conformational change in AmpR to promote expression of ampC (Jones and Bennett, 1995; Caille et al., 2014). It has been found that most of class A $\beta$-lactamases are also regulated by LysR family regulators (see reviews of Bush et al., 1995; Philippon et al., 2016). Expressions of some inducible class A $\beta$-lactamase genes (e.g., $n m c A, c u m A, s m e A$, cdiA, sed-1, $\operatorname{hug} A$, and pen $A$ ) are ultimately controlled by cognate LysR family transcriptional regulators, and these $\beta$-lactamase genes located nearby $l y s R$ and transcribed divergently (Datz et al., 1994; Naas and Nordmann, 1994; Jones and Bennett, 1995; Naas et al., 1995; Trépanier et al., 1997; Petrella et al., 2001; Liassine et al., 2002; Poirel et al., 2009).

Previous studies have shown that the $[\mathrm{Fe}-\mathrm{S}]$ cluster biosynthesis-related genes are involved in antibiotic susceptibility in Escherichia coli. Bactericidal agents (quinolones, aminoglycosides, and $\beta$-lactams) were proposed to induce oxidative stress and produce reactive oxygen species (ROS), thereby destabilizing the $\mathrm{Fe}-\mathrm{S}$ clusters and resulting in $\mathrm{Fe}(\mathrm{II})$ mediated Fenton reactions (Dwyer et al., 2009). Disruption of the $\mathrm{Fe}-\mathrm{S}$ cluster biosynthesis genes iscS, isc $U$, $h s c A, h s c B$, and $f d x$ increased susceptibility to various antibiotics (e.g., cephalosporins, penicillins, and glycopeptides) in E. coli (Liu et al., 2010). IscR was discovered as a negative regulator controlling the Fe-S biogenesis system (Schwartz et al., 2001). It is widely conserved in Proteobacteria and is proposed to be a member of the large Rrf2 family of winged helixturn-helix (wHTH) transcription factors (Schwartz et al., 2001). Recently, we showed that a transposon (Tn5) insertion in a gene encoding $\mathrm{Fe}-\mathrm{S}$ cluster assembly regulator (iscR) affected selenite susceptibility and antimonite oxidation in Comamonas testosteroni S44 (Zheng et al., 2014; Liu H.L. et al., 2015). IscR is also reported to regulate more than 40 genes that are involved in various cellular processes in
E. coli (Giel et al., 2006, 2013; Haines et al., 2015). Thus, IscR may be associated with the regulation of antibiotic susceptibility.

Comamonas testosteroni strains are primarily environmental bacteria that play an important role in environmental decontamination, having the ability to transform heavy metals and degrade a variety of toxic aromatic pollutants (Liu L. et al., 2015). Recently, C. testosteroni strains have also been recognized as human pathogens with potential to cause blood, endocardial, and abdominal infections (Duran et al., 2015; Parolin et al., 2016). Empiric therapy includes use of intravenous antibacterials of $\beta$-lactams and fluoroquinolones, especially cefoxitin and ciprofloxacin (Duran et al., 2015; Parolin et al., 2016). C. testosteroni S44 was isolated from the soil of an antimony ( $\mathrm{Sb}$ ) mine and is resistant to multiple heavy metals (Xiong et al., 2011) and some antibiotics, including cefalexin, cefazolin, benzylpenicillin, and ampicillin (unpublished data). The objective of this study was to elucidate the IscR-/CzoR-mediated regulatory mechanism of a newly identified Class A $\beta$-lactamase CzoA in C. testosteroni S44. Based on a gene knock-out and its complementation, electrophoretic mobility shift assay (EMSA), DNase I footprinting, and lacZ reporter gene assays, we found that the LysR-type transcriptional regulator CzoR positively regulates $c z o A$ expression and that IscR enhances this regulatory effect through binding with the $c z o R$ promoter region.

\section{MATERIALS AND METHODS}

\section{Bacterial Strains, Plasmids, and Culture Conditions}

Bacterial strains, plasmids, and oligonucleotide primers used in this study are shown in Supplementary Table S1. All strains were grown at $37^{\circ} \mathrm{C}$ in Luria-Bertani (LB, Oxoid, United Kingdom) broth unless otherwise stated. Mueller-Hinton ( $\mathrm{MH}$, Beijing Land Bridge Technology, China) broth dilution was used to determine the minimal inhibitory concentration (MIC) of antibiotics. Antibiotic disk (Hangzhou Microbial Reagent, China) diffusion tests were used for the antibiotic susceptibility assay (cephalexin and cefazolin). Appropriate antibiotic agents were added when preparing the seed liquid of all bacteria possessing a plasmid. Then, the seed liquid was used directly in relevant experiments.

\section{Bioinformatic Analysis}

Whole-genome shotgun sequencing was performed using a Roche 454 Genome Sequencer FLX instrument as described previously (Xiong et al., 2011). Multiple amino acid sequence alignments of CzoA with representative Class A $\beta$-lactamases and CzoR with its homologs were conducted using Clustal Omega ${ }^{1}$. The IscR-binding site was analyzed by the online program $\mathrm{MEME}^{2}$ (Bailey and Elkan, 1994). The -35 and -10 sequences were

\footnotetext{
${ }^{1}$ http://www.ebi.ac.uk/Tools/msa/clustalo/

${ }^{2}$ http://meme-suite.org/tools/meme
} 
predicted using Softberry BPROM Tool ${ }^{3}$ (Solovyev and Salamov, 2011).

\section{Construction of iscR and czoR Mutants and Complemented Strains}

The iscR-mutant strain iscR-280 and its complemented strain iscR-280C were generated in our previous study (Liu H.L. et al., 2015). To create a $c z o R$-mutant strain, the suicide allelic exchange vector pCM184-Cm was used as previously described (Chen et al., 2015). The upstream and downstream regions of $c z o R$ were amplified with the primer pairs $\mathrm{M}$ $c z o R$-up-F/M-czoR-up-R and M-czoR-down-F/M-czoR-down-R, respectively. Subsequently, the upstream and downstream PCR fragments were cloned into the AatII-BsrGI and ApaI-SacI sites of pCM184-Cm, respectively. The resulting $c z o R$ allelic exchange vector $\mathrm{pCM} 184-c z o R$ was introduced into the strain S44 via biparental conjugation with the E. coli strain S171 (ipir) (Simon et al., 1983), and the double crossover $c z o R$ mutant was selected using $50 \mu \mathrm{g} / \mathrm{ml}$ chloramphenicol and $25 \mu \mathrm{g} / \mathrm{ml}$ tetracycline. The tetracycline-sensitive and chloramphenicol-resistant mutant was then confirmed by PCR using primers $c z o R$-inner-F/czoR-inner-R (Supplementary Table S1). For $c z o R$ complementation, the complete $c z o R$-coding sequence was amplified via PCR and digested with $\mathrm{XbaI}$ and EcoRI. The fragment was subcloned into the broad host-range vector pCPP30, generating plasmid pCPP30::czoR. Then, the pCPP30::czoR plasmid was transferred into the $\Delta c z o R$ strain by biparental conjugation (Simon et al., 1983) to yield the complemented strain $\triangle c z o R$-C.

\section{Purification of $\mathrm{His}_{6}-\mathrm{CzoA}, \mathrm{His}_{6}-\mathrm{IscR}$, and His $_{6}-$ CzoR}

Expression and purification of the recombinant $\mathrm{His}_{6}-\mathrm{CzoA}$, $\mathrm{His}_{6}$-IscR, and $\mathrm{His}_{6}$-CzoR proteins were conducted as described previously (Liu H.L. et al., 2015). Complete coding regions of CzoA, IscR, and CzoR were PCR amplified and subcloned into the His-tag expression vectors pET-28a $(+)$ (CzoA and IscR) or pET-32a $(+)$ (CzoR) (Novagen), yielding plasmids pET-28a(+)-CzoA, pET-28a(+)-IscR, and pET-32a(+)-CzoR (Supplementary Table S1). The recombinant plasmids were introduced via transformation into the E. coli strain BL21 (DE3). CzoA, IscR, and CzoR were overexpressed by adding $0.08 \mathrm{mM}$ isopropyl $\beta$-D-1-thiogalactopyranoside (IPTG) at an $\mathrm{OD}_{600}$ of 0.2 and further culturing strains for $8 \mathrm{~h}$ at $28^{\circ} \mathrm{C}$. Induced cells were then harvested by centrifugation and lysed in a French Press (JN-02C, JNBIO, China) in lysis buffer $[50 \mathrm{mM}$ Tris- $\mathrm{HCl}(\mathrm{pH}$ 7.5) and $150 \mathrm{mM}$ $\mathrm{NaCl}$. Soluble supernatant was mixed with $1 \mathrm{ml}$ of nickelnitrilotriacetic acid-agarose solution (Qiagen) and eluted in $1 \mathrm{ml}$ of elution buffer [200 $\mathrm{mM}$ imidazole, $50 \mathrm{mM}$ Tris-HCl (pH 7.5), and $150 \mathrm{mM} \mathrm{NaCl}$. After dialysis to remove imidazole, purified proteins were stored in $15 \%$ glycerol at $-80^{\circ} \mathrm{C}$. For in vitro enzymatic assay, $\mathrm{His}_{6}$ tag of recombinant $\mathrm{His}_{6}-\mathrm{CzoA}$ were excised by addition of $0.5 \mathrm{U} / \mathrm{ml}$

${ }^{3} \mathrm{http}: / /$ linux 1. softberry.com/berry.phtml?topic=bprom\&group=programs\& subgroup $=$ gindb bovine thrombin (Sigma-Aldrich, Buchs, Switzerland) and incubated at $4^{\circ} \mathrm{C}$ for $8 \mathrm{~h}$, followed by dialysis in buffer [50 mM Tris- $\mathrm{HCl}(\mathrm{pH} 7.5)$ and $150 \mathrm{mM} \mathrm{NaCl}$ (Guan et al., 2017).

\section{Enzyme Hydrolysis Assay and Inhibition of $\beta$-Lactamase Activity}

Hydrolysis activities of $11 \beta$-lactams (benzylpenicillin, ampicillin, cefalexin, cefazolin, cefuroxime, cefoxitin, ceftazidime, ceftriaxone, cefepime, meropenem, and imipenem) by CzoA without $\mathrm{His}_{6}$ tag were determined. $\mathrm{His}_{6}$-excised $\mathrm{CzoA}$ $(0.01 \mu \mathrm{mol} / \mathrm{l})$ and various concentrations $(20-600 \mathrm{mmol} / \mathrm{l})$ of each $\beta$-lactam were added to PBS buffer ( $\mathrm{pH} 7.0)$, and incubated at $30^{\circ} \mathrm{C}$ for $30 \mathrm{~min}$. The hydrolysis activities were evaluated through the changes in characteristic absorbance for the 11 $\beta$-lactams using a spectrophotometer (DU 800, Beckman, United States) (Lamoureaux et al., 2013). $K_{\mathrm{m}}$ values were determined by the Lineweaver-Burk plot (Bush and Sykes, 1986). Three technical and biological replicates were performed for each reaction.

Minimal inhibitory concentration profiles of the recombinant E. coli DH5 $\alpha$ (Miller and Mekalanos, 1988) expressing $c z o A$ (pCT-Zori::czoA) and the isogenic strains of C. testosteroni S44 (S44, $\Delta c z o R, \Delta c z o R-\mathrm{C}, \Delta i s c R$, and $\Delta i s c R-\mathrm{C}$ ) were determined by the broth dilution method (Clinical and Laboratory Standards Institute, 2014) using $11 \beta$-lactams. For the recombinant $E$. coli $\mathrm{DH} 5 \alpha$, two $\beta$-lactamase inhibitors, clavulanic acid, and tazobactam were also tested. E. coli DH5 $\alpha$ (pCT-Zori) was used as a control. Clavulanic acid and tazobactam were generally fixed at a concentration of 2 and $4 \mu \mathrm{g} / \mathrm{ml}$, respectively (Girlich et al., 2007; Naas et al., 2007; Lamoureaux et al., 2013; Clinical and Laboratory Standards Institute, 2014). Moreover, growth tendency of the isogenic strains of S44 under stress of $11 \beta$-lactams with concentration below MIC was evaluated through $\mathrm{OD}_{600}$ values. Isogenic strains of C. testosteroni S44 in exponential growth phase were inoculated with each of $11 \beta$-lactams in $\mathrm{MH}$ medium at $37^{\circ} \mathrm{C}$ and $\mathrm{OD}_{600}$ values were determined using a spectrophotometer after growth for $24 \mathrm{~h}$.

\section{Disk Diffusion Susceptibility Testing}

The disk diffusion method was used for an antibiotic susceptibility assay (Jorgensen et al., 1999). Antimicrobial disks impregnated with cefalexin or cefazolin were separately placed onto the inoculated $\mathrm{MH}$ agar plates. After being incubated at $37^{\circ} \mathrm{C}$ for $36 \mathrm{~h}$, an inhibition zones around each antibiotic disk was measured. In addition, a spotting dilution assay was performed to determine the susceptibility of strains to cefalexin and cefazolin. Overnight cultures of strains S44, iscR-280, iscR-280C, $\triangle c z o R$, and $\Delta c z o R$-C were grown in LB medium. Tenfold gradient dilutions of these strains $\left(\mathrm{OD}_{600}=1.0\right)$ were each plated $(4 \mu \mathrm{l})$ onto solid $\mathrm{LB}$ medium containing $50 \mu \mathrm{g} / \mathrm{ml}$ of cefalexin or cefazolin. LB medium without antibiotics was used as a control. Agar plates were incubated at $37^{\circ} \mathrm{C}$ and photographed daily until colonies formed. 


\section{Electrophoretic Mobility Shift Assay (EMSA)}

The intergenic region of $c z o R-c z o A$ was PCR amplified with primers EMSA-CzoR-F and EMSA-CzoR-R (Supplementary Table S1). The primer EMSA-CzoR-F was labeled with the fluorophore 5-carboxyfluorescein (FAM, Tsingke Biological Technology Company, Wuhan, China). To identify exact binding sequences of IscR, a 30 bp FAM-labeled DNA was synthesized (Tsingke Biological Technology Company, Wuhan, China) and directly annealed in vitro. For EMSA, the purified $\mathrm{His}_{6}-\mathrm{CzoR}$ and $\mathrm{His}_{6}$-IscR were each incubated with FAM-labeled DNA in $30 \mu \mathrm{l}$ of incubation buffer [100 mM HEPES, $\mathrm{pH}$ 7.6, $5 \mathrm{mM}$ ethylene diamine tetra acetic acid (EDTA), $50 \mathrm{mM}\left(\mathrm{NH}_{4}\right)_{2} \mathrm{SO}_{4}$, $5 \mathrm{mM}$ dithiothreitol (DTT), Tween 20,1\% (w/v), and $150 \mathrm{mM}$ $\mathrm{KCl}]$ at $28^{\circ} \mathrm{C}$ for $30 \mathrm{~min}$. After incubation, the mixtures were electrophoresed in an $8 \%$ native polyacrylamide gel in $1 \times$ Tris/Borate/EDTA (TBE) buffer for $1 \mathrm{~h}$. The gels were then exposed using a phosphorimaging system (Fujifilm FLA-5100, United States).

\section{DNase I Footprinting Assay}

To identify exact CzoR-binding sites within the intergenic region of $c z o R-c z o A$, a DNase I footprinting experiment was performed as described previously (Shi et al., 2017). The binding reaction was carried out in a $30 \mu \mathrm{l}$ system containing 0 or $0.12 \mathrm{nM}$ of purified CzoR and $100 \mathrm{ng}$ of $5^{\prime}$-FAM labeled DNA fragment. After an incubation at $28^{\circ} \mathrm{C}$ for $30 \mathrm{~min}$, DNase I ( 0.8 unit in $20 \mu$ l, Promega) was added to the binding mixture and incubated at $37^{\circ} \mathrm{C}$ for $10 \mathrm{~min}$. Then, the reaction was terminated by adding $10 \mu \mathrm{l}$ of $50 \mathrm{mM}$ EDTA and an incubation in a water bath at $65^{\circ} \mathrm{C}$ for $10 \mathrm{~min}$. Digested DNA fragments were purified using a NucleicSpin Gel and PCR Clean-up Kit (Macherey-Nagel, Germany) and analyzed with an Applied Biosystems 3730XL DNA Analyzer (Tsingke Biological Technology Company, Wuhan, China). Results were analyzed with GeneMarkerV1.6536 (Shi et al., 2017).

\section{czoA::lacZ Reporter Gene Assays}

The $c z o A$ promoter $\left(\mathrm{P}_{c z o A}\right)$ region was amplified by PCR using the primers pLSP-czoA-F and pLSP-czoA-R (Supplementary Table S1). The PCR amplicon was then digested with EcoRI and $B a m \mathrm{HI}$ and directionally cloned into the lac $Z$ reporter plasmid pLSPkt2lacZ, which was transformed into E. coli S17-1( $\lambda$ pir) (Supplementary Table S1). The resulting plasmid pLSP-czoA was introduced into strains S44, iscR-280, iscR-280C, $\triangle c z o R$, and $\Delta c z o$ R-C via biparental conjugation (Simon et al., 1983). All strains were inoculated into LB medium with or without addition of $\beta$-lactams. After being incubated at $37^{\circ} \mathrm{C}$ for $8 \mathrm{~h}$, $\beta$-galactosidase activities were measured as previously described (Liu H.L. et al., 2015).

\section{Real-Time Quantitative RT-PCR}

Each strain of S44, iscR-280, iscR-280C, $\Delta c z o R$, and $\triangle c z o R-C$ was each inoculated into LB medium and incubated at $37^{\circ} \mathrm{C}$ for $8 \mathrm{~h}$. Next, 0 or $25 \mu \mathrm{g} / \mathrm{ml}$ of cefalexin or cefazolin was added to the culture. After $1 \mathrm{~h}$ of induction, bacterial cells were harvested for total RNA extraction using TRIzol Reagent (Invitrogen, Grand Island, NY, United States) according to the manufacturer's instructions (Invitrogen, Grand Island, NY, United States). Real-time RT-PCR was carried out using an Applied Biosystems ${ }^{\circledR}$ ViiA $^{\text {TM }} 7$ Real-Time PCR System (Life Technologies, Carlsbad, CA, United States) and primers listed in Supplementary Table S1. Gene expression was normalized by the $\Delta \Delta \mathrm{CT}$ method with an iQ5 Real-Time PCR Detection System (Bio-Rad, United States) (Pfaffl, 2001). An ATP-binding subunit encoding gene clpX (CTS44_RS19450) was used as a reference (Caille et al., 2014) and three technical and biological replicates were performed for each reaction. Statistically significant difference between control and treated samples was performed using Student's $t$-test with $P<0.01$ as borderline and $P<0.01$ as statistically significant level. Data are expressed as the average of three experiments.

\section{RESULTS}

\section{Genetic Organization of $c z o R$ and iscR}

In this study, a novel putative class A $\beta$-lactamase gene, we named $c z o A$ here (czo for cefazolin), was found from the draft genome of C. testosteroni S44 (ADVQ00000000.1, Xiong et al., 2011). CzoA consists of 301 deduced amino acids and shows high similarities with several established class A $\beta$-lactamases, PenA (AAB53622.1, 47\%), NmcA (AOW71300.1, 43\%), AST-1 (AAG44836.1, 43\%), Sed-1 (WP_063864602.1, 43\%), CdiA (CAA54738.1, 43\%), BlaA (AIK22395.1, 43\%), GIL-1 (WP_063860521.1, 41\%), and HugA (AAL57765.1, 40\%). A multiple sequences alignment showed that CzoA shares conserved residues $\left(\mathrm{E}^{166}\right.$ and $\mathrm{R}^{220}$ ) and motifs $\left(\mathrm{S}^{70} \mathrm{XXK}^{73}, \mathrm{~S}^{130} \mathrm{DN}\right.$, and $\left.\mathrm{K}^{234} \mathrm{TG}\right)$ with other class $\mathrm{A} \beta$-lactamases (Supplementary Figure S1). No obvious differences were detected among MICs of the wild-type strain S44 (Supplementary Table S2) and $\triangle c z o R$ or $\triangle i s c R$ (data not shown), possibly because there are two other putative $\beta$-lactamases of class $B$ (WP_003070075.1) and class D (WP_034361410.1) in S44. Class $\mathrm{B}$ and Class $\mathrm{D} \beta$-lactamases showed overlapping substrate profiles compared with Class A $\beta$-lactamase (Bush and Jacoby, 2010). Therefore, knock-out and complementation experiments of $c z o A$ were not performed.

A LysR family transcriptional regulator encoding gene, here named $c z o R$, located immediately upstream of $c z o A$ was also identified (Figure 1). CzoR displays the highest amino acid identity (59\%) with AmpR of Pseudomonas aeruginosa using BlastP analysis (Caille et al., 2014). Sequence alignments of CzoR with AmpR (ADB64523.1, 59\%), PenR (AAB53621.1, 57\%), SedR (AAK63224.1, 56\%), CdiR (CAA54736.1, 55\%), HugR (AAL57764.1, 49\%), and NmcR (AOW71475.1, 45\%) were performed (Supplementary Figure S2). No putative CzoRbinding motifs were predicted using online program MEME, however, we found a putative CzoR-binding box in the promoter region of $c z o A$ using EMSA and DNase I footprinting assays, suggesting that CzoR may regulate $c z o A$ expression (Figure 1). In addition, to investigate the effect of the Fe-S cluster assembly regulator encoding gene iscR on antibiotic susceptibility, the Fe-S cluster biosynthesis-related genes were also analyzed. The S44 


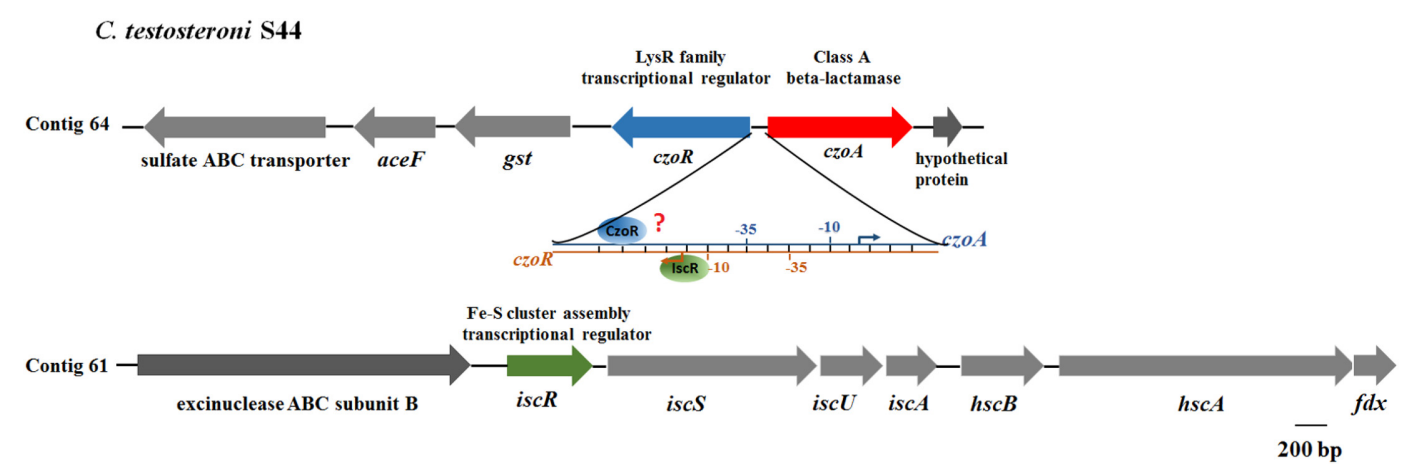

FIGURE 1 | Genetic organization of $c z O R$ and iscR. The $c z O R$ and $c z O A$ genes form a divergent operon (czoR-czoA) located in contig 64 . The isc operon of S44 is composed of the iscRSUA-hscBA-fdx genes and is located in contig 61. The diagram shows that both IscR and CzoR can bind to the $c z 0 R-c z O A$ intergenic region, but the precise binding sites of CzoR are unknown. The -35 and -10 sequences were predicted using Softberry BPROM webtool (Solovyev and Salamov, 2011).

genome contains only one isc system, which is composed of the iscRSUA-hscBA-fdx genes located in contig 61 (Figure 1). IscR-binding motif varies among bacteria originated from different taxa (Novichkov et al., 2013). Based on IscR-binding motifs (5'-WTAMYYRNSNVDWWYRVWMRRBWWH-3') in C. testosteroni KF-1 obtained from the RegPrecise database (Novichkov et al., 2013), we found a putative IscR-binding site within the $c z o R-c z o A$ intergenic region using online program MEME (Bailey and Elkan, 1994), suggesting that IscR may also be involved in the regulation of $c z o R / A$.

\section{Antibiotic Susceptibility}

Considering $C$. testosteroni S44 contains multiple $\beta$-lactamases, we determined MICs of various $\beta$-lactam antibiotics against E. coli DH5 $\alpha$ (pCT-Zori::czoA) expressing CzoA. MIC tests using a conventional broth dilution method indicated that the recombinant strain produced the $\beta$-lactamase and its activity was inhibited by clavulanic acid or tazobactam. Determination of MICs of $\beta$-lactams for E. coli DH5 $\alpha$ (pCT-Zori::czoA) showed that it was resistant to benzylpenicillin, ampicillin, and some cephalosporins such as cefalexin, cefazolin, cefuroxime, ceftriaxone, cefepime, and imipenem, but it remained susceptible to cefoxitin, ceftazidime, and meropenem (Table 1). The MICs of benzylpenicillin, ampicillin, ceftriaxone, and cefepime were significantly reduced by both tazobactam and clavulanic acid, while these of cefalexin, cefazolin, and cefuroxime were merely reduced by clavulanic acid (Table 1), and the others were not inhibited by tazobactam or clavulanic acid (data not shown in Table 1). It is interesting that MIC of ampicillin-tazobactam was 16-fold of that of ampicillin-clavulanic acid (Table 1), which indicated clavulanic acid is a sound inhibitor for class A $\beta$-lactamases, while tazobactam is a good inhibitor for other class of $\beta$-lactamase.

\section{CzoA Kinetics Analysis}

Kinetic parameters of the CzoA $\beta$-lactamase obtained with the purified enzyme (without His 6 tag) (Supplementary Figure S3) showed that CzoA had strong activities ( $k_{\text {cat }}$ values of 99-1085 $\mathrm{s}^{-1}$ ) to degrade benzylpenicillin, ampicillin, and cefazolin. Cefalexin, cefuroxime, ceftriaxone, and cefepime were hydrolyzed at low levels ( $k_{\text {cat }}$ values of $2-12 \mathrm{~s}^{-1}$ ), whereas hydrolysis of cefoxitin, ceftazidime, meropenem, and imipenem was not detectable (Table 2). These results are in agreement with

TABLE 1 | $\beta$-Lactam activity against $E$. coli DH5 $\alpha$ expressing CzoA.

\begin{tabular}{|c|c|c|c|}
\hline \multirow[b]{2}{*}{ Antibiotic } & \multicolumn{2}{|c|}{ MIC $(\mu \mathrm{g} / \mathrm{ml})$} & \multirow[b]{2}{*}{$\begin{array}{c}\text { Fold difference } \\
\text { pCT-Zori::czoA } \\
\text { /pCT-Zori }\end{array}$} \\
\hline & $\begin{array}{l}\text { E. coli DH5 } \alpha \\
\text { (pCT- } \\
\text { Zori::czoA) }\end{array}$ & $\begin{array}{c}\text { E. coli } \\
\text { DH5 } \alpha \\
\text { (pCT-Zori) }\end{array}$ & \\
\hline Benzylpenicillin & 2048 & 8 & 256 \\
\hline Benzylpenicillin + TZBa & 512 & 8 & 64 \\
\hline Benzylpenicillin $+C L A^{b}$ & 64 & 8 & 8 \\
\hline Ampicillin & 2048 & 2 & 1024 \\
\hline Ampicillin + TZB & 128 & 2 & 64 \\
\hline Ampicillin + CLA & 8 & 2 & 4 \\
\hline Cefalexin & 1024 & 8 & 128 \\
\hline Cefalexin + CLA & 128 & 8 & 16 \\
\hline Cefazolin & 512 & 8 & 64 \\
\hline Cefazolin + CLA & 32 & 8 & 4 \\
\hline Cefuroxime & 128 & 8 & 16 \\
\hline Cefuroxime + CLA & 8 & 8 & 1 \\
\hline Cefoxitin & 8 & 8 & 1 \\
\hline Ceftazidime & 2 & 2 & 1 \\
\hline Ceftriaxone & 128 & 0.5 & 256 \\
\hline Ceftriaxone + TZB & 8 & 0.5 & 16 \\
\hline Ceftriaxone + CLA & 2 & 0.5 & 4 \\
\hline Cefepime & 16 & 0.25 & 64 \\
\hline Cefepime + TZB & 4 & 0.25 & 16 \\
\hline Cefepime + CLA & 1 & 0.25 & 4 \\
\hline Meropenem & 0.031 & 0.031 & 1 \\
\hline Imipenem & 1 & 0.125 & 8 \\
\hline Tazobactam & 32 & 32 & 1 \\
\hline Clavulanic acid & 64 & 64 & 1 \\
\hline
\end{tabular}

a TZB, tazobactam at a fixed concentration of $4 \mu \mathrm{g} / \mathrm{ml} .{ }^{\mathrm{b}} \mathrm{CLA}$, clavulanic acid at a fixed concentration of $2 \mu \mathrm{g} / \mathrm{ml}$; data are expressed as the average of three independent experiments. 
TABLE 2 | Steady-state kinetic parameters for hydrolyses of $\beta$-lactam substrates by the native CzoA.

\begin{tabular}{lccc}
\hline Substrate & $\boldsymbol{K}_{\mathbf{m}}(\mathbf{m M})$ & $\boldsymbol{k}_{\mathbf{c a t}}\left(\mathbf{s}^{-\mathbf{1}}\right)$ & $\boldsymbol{k}_{\mathbf{c a t}}\left(\mathbf{s}^{-\mathbf{1}}\right) \boldsymbol{K}_{\mathbf{m}}\left(\mathbf{m M}^{-\mathbf{1}} \mathbf{s}^{-\mathbf{1}}\right)$ \\
\hline Benzylpenicillin & $2.17 \pm 0.4$ & $738 \pm 14$ & $349 \pm 9$ \\
Ampicillin & $5.69 \pm 0.1$ & $99 \pm 3$ & $18 \pm 0.2$ \\
Cefalexin & $0.33 \pm 0.02$ & $12 \pm 1$ & $36 \pm 2$ \\
Cefazolin & $2.25 \pm 0.2$ & $1085 \pm 16$ & $505 \pm 20$ \\
Cefuroxime & $0.37 \pm 0.02$ & $8 \pm 0.5$ & $22 \pm 0.1$ \\
Cefoxitin & - & - & - \\
Ceftazidime & - & - & - \\
Ceftriaxone & $0.24 \pm 0.007$ & $3 \pm 0.05$ & $7 \pm \pm 0.2$ \\
Cefepime & $0.30 \pm 0.02$ & $2 \pm 0.6$ & - \\
Meropenem & - & - & - \\
Imipenem & - & - & - \\
\hline
\end{tabular}

Data are expressed as the average of three independent experiments $\pm S D$. - , not determinable.

antibiotic susceptibility testing that CzoA did not show obvious hydrolyzing activity for cefoxitin, ceftazidime, and meropenem. However, for imipenem, the MIC difference was observed (1 vs. $0.125 \mu \mathrm{g} / \mathrm{ml})$, which indicates imipenem may be a substrate of CzoA (Table 1).

\section{Effects of $c z o A / R$ and IscR under Different Antibiotics}

Expression of $c z o A:: l a c Z$ was significantly induced by all 11 $\beta$-lactams tested (Figure 2A), although CzoA did not show obvious hydrolysis activity of cefoxitin, ceftazidime, meropenem, and imipenem in vitro (Table 2). Substrate induction experiments indicated that $\mathrm{CzoA}$ was an inducible class A $\beta$-lactamase in presence of $\beta$-lactams. Transcription level of $c z o R$ was significantly induced by nine $\beta$-lactams, but not inducible by cefuroxime and cefoxitin (Figure 2B); however, czoR still showed constitutive transcriptions without and with addition of cefuroxime and cefoxitin (Figure 2B).

To further investigate effects of $\mathrm{CzoR}$ and IscR on cephalosporin susceptibility, a mutant strain $\triangle c z o R$ and its complemented strain $\triangle c z o R-C$ were constructed. Successful deletion and complementation of $c z o R$ were confirmed by diagnostic PCR, as shown in Supplementary Figure S4. An iscR-mutant strain iscR-280 ( $\triangle i s c R)$ and a complemented strain iscR-280C ( $\triangle i s c R-\mathrm{C})$ were obtained from our previous study (Liu H.L. et al., 2015). Both mutant strains $\triangle c z o R$ and $\Delta i s c R$ showed significantly inhibited growth compared to S44 under a certain concentration of different $\beta$-lactams (Figure 2C). Antibiotic susceptibility phenotype of complemented strains $\Delta c z o R-\mathrm{C}$ and $\Delta i s c R-\mathrm{C}$ was mostly recovered (data not shown).

\section{Effects of iscR and $c z o R$ on Cefalexin and Cefazolin Susceptibility}

Real-time RT-PCR assays were performed in S44 with or without addition of cefalexin and cefazolin. Results showed that, similar to $c z o A$ and $c z o R$, iscR expression was also significantly induced by cefalexin and cefazolin (Figure $\mathbf{3 A}$ ), indicating iscR is also involved in cefalexin and cefazolin susceptibility. Kirby-Bauer disk diffusion assays showed that growth inhibition zones of $\triangle c z o R$ - and iscR-280-mutant strains were significantly larger than S44 in presence of cefalexin and cefazolin (Figure 3B). Antibiotic susceptibility phenotypes of complemented strains were restored (Figure 3B). In addition, spotting assays showed that the iscR-280 strain, and to a greater extent for the $\triangle c z o R$ strain, was more susceptible to cefalexin and cefazolin relative to the wild-type strain S44 (Figure 3C). Phenotypes of the complemented strains were restored, and all strains showed a similar growth trend on LB plates without antibiotics (Figure 3C). These results suggested that both IscR and CzoR are essential for cephalosporin susceptibility and that CzoR may play a more important role.

\section{CzoR Binds to the Promoter Region of CzoA}

To examine interactions between CzoR and PczoA, EMSA was performed with a 259 bp fragment of $\mathrm{P} c z o A$ and purified CzoR (Supplementary Figure S5). With an increasing CzoR concentration, free DNA substrates gradually disappeared, while intensity of shifted DNA bands increased (Figure 4A). Reactions using heat-denatured CzoR and a non-specific DNA probe did not show any lagging bands. Moreover, unlabeled czoA DNA substrates could competitively inhibit CzoR binding to the FAMlabeled $c z o A$ (Figure 4A). These results indicated that CzoR could specifically bind to the $c z o A$ regulatory region.

Subsequently, a DNase I footprinting assay was conducted to determine exact binding sites of CzoR. Results showed that the -88 to -72 region in $\mathrm{P} c z o A$ was obviously protected from DNase I digestion (Figure 4B), indicating that a $17 \mathrm{bp}$ fragment $\left(5^{\prime}\right.$-TCTCAATCAAGATAAAA-3') upstream of $c z o A$ was a CzoR-binding box in S44 (Figure 4C). For further confirmation, interactions between CzoR and a 211 bp fragment of PczoA without CzoR-binding box were tested. EMSA results showed that there was no band shift without CzoR-binding box (Figure 4D). These experiments demonstrated that the LysR family regulator CzoR can regulate the class A $\beta$-lactamase gene $c z o A$ in $\mathrm{S} 44$.

\section{IscR Binds to the Regulatory Region of CzoR-CzOA}

Based on IscR-binding motifs in C. testosteroni KF-1 obtained from the RegPrecise database (Novichkov et al., 2013), we found a putative IscR-binding site within $c z o R-c z o A$ intergenic region. A putative IscR motif (TTTTCTAATGGATGGTGTCAATTAT) was located in the sense strand adjacent to the CzoR box (Figure 5A). The interaction between IscR and $c z o R-c z o A$ intergenic region was examined by EMSA. With an increasing IscR concentration, lagging bands were clearly observed. In contrast, negative controls (non-specific DNA probe or heatdenatured IscR) did not show any lagging bands (Figure 5B). In addition, IscR was capable of binding to substrates containing a 30 bp sequence with a refined IscR-binding motif (Figure 5C). These data suggest that IscR can directly bind to the $c z o R-c z o A$ promoter region, and may regulate the expression of both $c z o R$ and $c z o A$. 

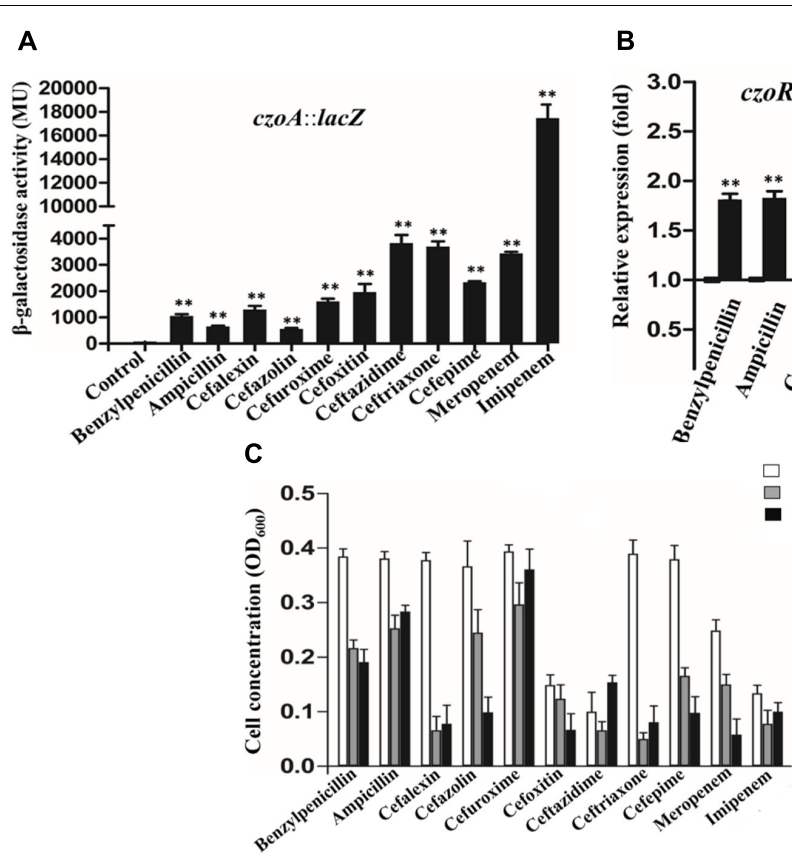

\section{B}

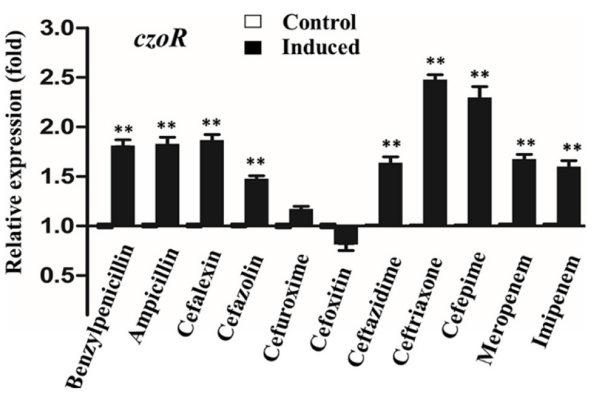

$\square$ S44

$\square$ iscR-280

- $\Delta c z o R$

FIGURE 2 | czOA and czoR were induced by different $\beta$-lactams. (A) A lacZ reporter fusion of $c z O A$. Bacteria were cultured in LB medium with addition of $25 \mu \mathrm{g} / \mathrm{ml}$ benzylpenicillin, ampicillin, cephalexin, cefazolin, cefuroxime, cefoxitin, ceftazidime, ceftriaxone, cefepime, and $0.5 \mu \mathrm{g} / \mathrm{ml}$ meropenem and imipenem. A culture without $\beta$-lactams was used as a control. (B) Real-time RT-PCR results for $c z O R$ in S44. The relative $c z o R$ mRNA expression levels induced by $11 \beta$-lactams (black bars) and in the control (without induction, white bars) were determined as described in the Section "Materials and Methods." Error bars represent standard deviations of triplicate tests. The selected induction concentrations, which did not affect normal growth, were well below the MIC for the $\beta$-lactams. **Indicates a significant difference from the control $(p<0.01$, Student's $t$-test). (C) The growth tendency of the isogenic strains of S44 under the stress of the $11 \beta$-lactams [benzylpenicillin $(2048 \mu \mathrm{g} / \mathrm{ml})$, ampicillin $(2048 \mu \mathrm{g} / \mathrm{ml})$, cephalexin (1024 $\mu \mathrm{g} / \mathrm{ml})$, cefazolin $(2048 \mu \mathrm{g} / \mathrm{ml})$, cefuroxime $(128 \mu \mathrm{g} / \mathrm{ml})$, cefoxitin $(128 \mu \mathrm{g} / \mathrm{ml})$, ceftazidime $(128 \mu \mathrm{g} / \mathrm{ml})$, ceftriaxone $(1024 \mu \mathrm{g} / \mathrm{ml})$, cefepime $(512 \mu \mathrm{g} / \mathrm{ml})$, meropenem $(1 \mu \mathrm{g} / \mathrm{ml})$, and imipenem $(4 \mu \mathrm{g} / \mathrm{ml})]$ was evaluated through the $\mathrm{OD}_{600}$ values.

A

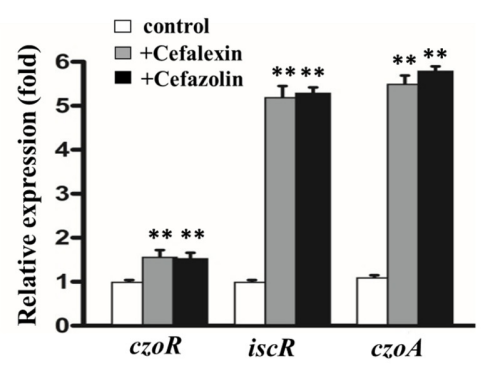

C
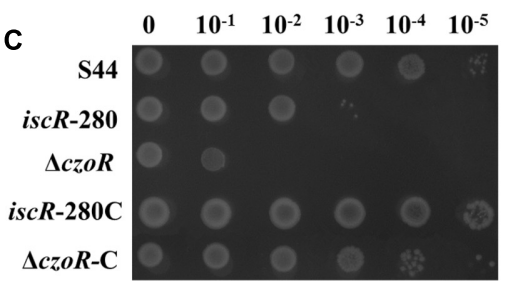

$50 \mu \mathrm{g} / \mathrm{mL}$ Cefalexin
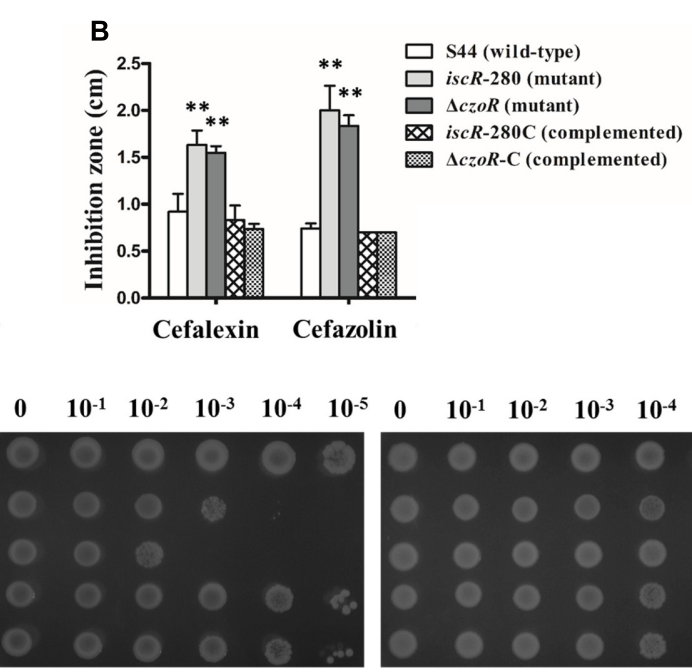

$50 \mu \mathrm{g} / \mathrm{mL}$ Cefazolin

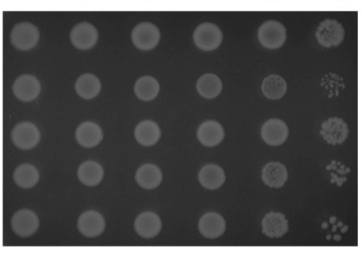

Control (LB medium)

FIGURE 3 | IscR and CzoR contribute to cephalosporin susceptibility. (A) Transcriptional levels of $c z O R$, iscR, and czoA in S44 with or without (white bars) addition of $25 \mu \mathrm{g} / \mathrm{ml}$ of cefalexin (dark gray bars) and cefazolin (black bars). (B) Susceptibility tests of strains S44, iscR-280, iscR-280C, $\Delta c z 0 R$, and $\Delta c z o R-C$ to different antibiotics (cefalexin and cefazolin) were determined using the Kirby-Bauer disk diffusion method. The inhibition zone of each disk was measured to the nearest millimeter. The diameter $(0.7 \mathrm{~cm})$ of susceptibility disks was counted in the inhibition zones. (C) Spotting assays for growths of strains S44, iscR-280, iscR-280C, $\triangle C z O R$, and $\triangle c z O R-C$ on LB plates without antibiotics and those supplemented with $50 \mu \mathrm{g} / \mathrm{ml}$ cefalexin or cefazolin. Ten-fold serial dilutions of each culture were inoculated on the plates and incubated at $37^{\circ} \mathrm{C}$ for $48 \mathrm{~h}$. Error bars represent standard deviations of triplicate tests. ${ }^{* *}$ Indicates a significant difference from the control $(p<0.01$, Student's $t$-test). 


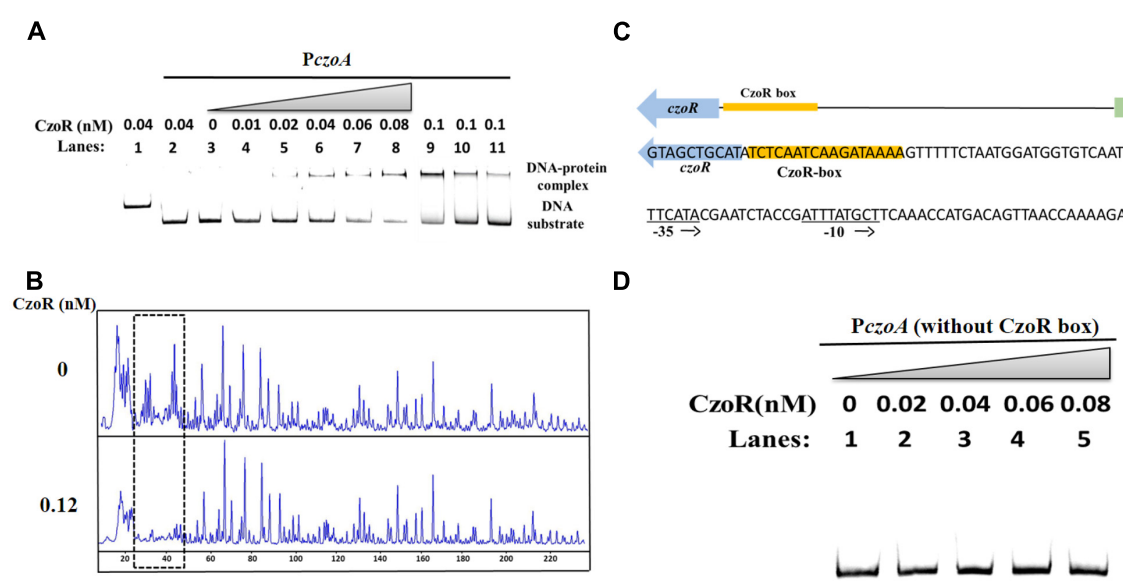

FIGURE 4 | EMSA and DNase I footprinting analyses of CzoR interaction with PCzOA. (A) Results of EMSA analysis of CzoR interaction with PCzoA. Bands 1-3 indicate negative controls: 1, DNA probe containing no CzoR-binding motif (non-specific DNA probe) in the presence of CzoR; 2, DNA probe containing PczoA (specific DNA probe) in the presence of heat-inactivated CzoR; 3, specific DNA probe only; Bands 4-8 represent 0.01, 0.02, 0.04, 0.06, and 0.08 nM of CzoR incubated with a specific DNA probe; Bands 9-11 represent the competition assay using 1.8 pmol of the FAM-label promoter region of czoA and 0.1 nM CzoR competed against 0, 3.6, and 8.0 pmol of unlabeled promoter region of CzOA. (B) Footprinting assay. The concentrations (nanomolar) of CzoR are indicated in the left lanes; reactions in each lane contained $100 \mathrm{ng}$ of the FAM-labeled PCzoA region with or without CzoR protein. The gridlines denote the regions protected by CzoR. (C) Sequence of the CzoR motif predicted by footprinting analysis. The CzoR box (yellow bars) and the PCzoA sites (-35 and -10) are indicated. (D) EMSA for the DNA-binding activity of CzoR and PCzOA without the CzoR box.

\section{A}

GTAGCTGCATATCTCAATCAAGATAAAAGTTTITCTAATGGATGGTGTCAATTATTACTGCTGG $\begin{array}{lll}c z o R & \text { CzoR-box } & \text { IscR-binding motif }\end{array}$

czoA

TTCATACGAATCTACCGATTTATGCTTCAAACCATGACAGTTAACCAAAAGAGGATCTTATGCA

B

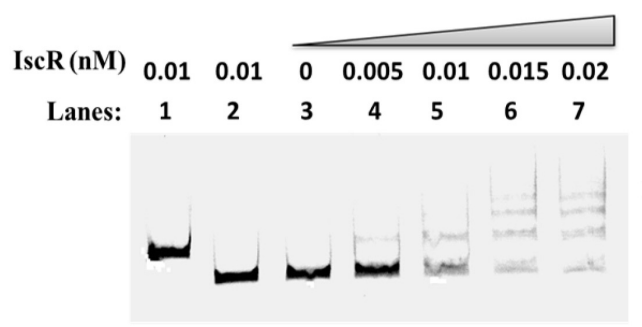

C

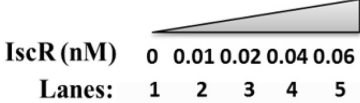

DNA-protein

complex

DNA

substrate

FIGURE 5 | EMSA analysis for the IscR interaction with the $c z O R-C z O A$ intergenic region. (A) IscR-binding motifs extracted from RegPrecise were used to identify potential IscR-regulated genes. A putative IscR-binding motif was located in the region between $c z O R$ and $c z O A$. (B) EMSA analysis results for the IscR interaction with the $c z O R-C z O A$ promoter. Bands 1-3 represent negative controls: 1, DNA probe containing no IscR-binding motif (non-specific DNA probe) in the presence of IscR; 2, DNA probe containing the putative IscR-binding motif (specific DNA probe) in the presence of heat-inactivated IscR; 3, specific DNA probe only; Bands 4-7 represent different concentrations of IscR added with a 1.8 pmol FAM-label of the DNA probe. (C) EMSA analysis results for the DNA-binding activity of IscR with a conserved 30 bp motif.

\section{CzoR Is Essential for czoA Expression and IscR Positively Regulates czoR Expression}

To investigate how iscR and $c z o R$ influence each other and further affect $c z o A$ expression, real-time RT-PCR transcription analyses were performed using $C$. testosteroni $\mathrm{S} 44$ isogenic strains with or without addition of cefalexin or cefazolin. Deletion of $i s c R$ significantly decreased $c z o R$ expression, and $c z o R$ was not induced by cefalexin and cefazolin in iscR-280-mutant strain (Figure 6A). $c z o R$ deletion did not affect transcription level of $i s c R$ (Figure 6B) indicating that $c z o R$ induction by cefalexin and cefazolin was depend on IscR expression. Phenotypes of the complemented strain $i s c R-280 \mathrm{C}$ were recovered.

Subsequent efforts focused on $c z o A$ expression in the isogenic strains of $C$. testosteroni S44 using a lacZ reporter 

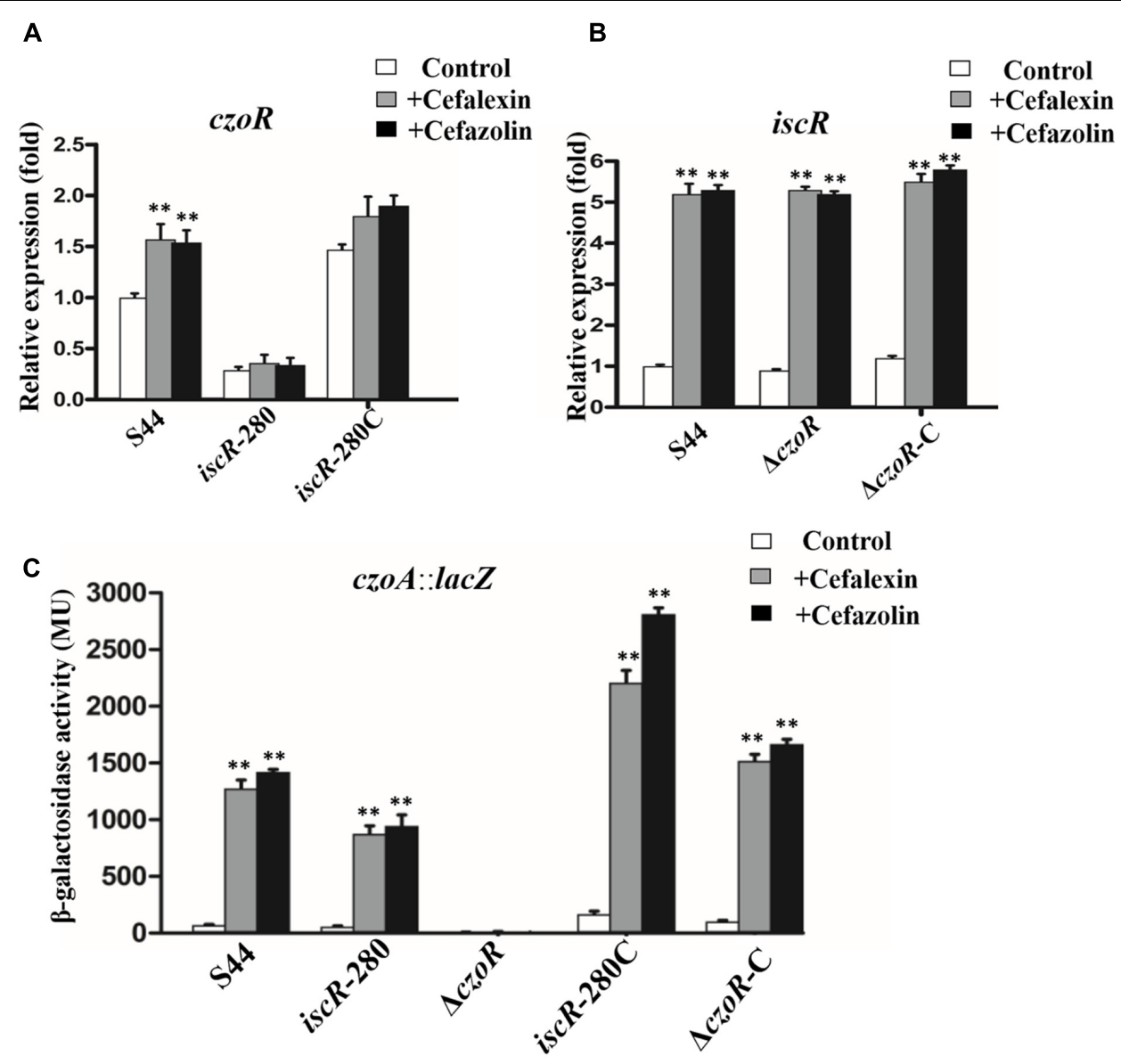

FIGURE 6 | Transcriptional analysis. (A,B) Represents real-time RT-PCR results for $c z O R$ and iscR. The relative $c z o R$ and isc $R$ mRNA expression levels induced by cefalexin (gray bars) and cefazolin (black bars) and in the control (without induction, white bars) were determined as described in the section "Materials and Methods." Error bars represent standard deviations of triplicate tests. (C) Shows a lacZ reporter fusion of $c z O A$. Bacteria were cultured in LB medium with or without (white bars) addition of $25 \mu \mathrm{g} / \mathrm{ml}$ cefalexin (gray bars) and cefazolin (black bars). **Indicates a significant difference from the control ( $p<0.01$, Student's $t$-test).

gene assay. Results showed that expression of $c z o A:: l a c Z$ was significantly induced by cefalexin and cefazolin in S44, consistent with induction expressions of $c z o R$ and $i s c R$ in presence of cefalexin and cefazolin (Figure 3A). Deletion of iscR (iscR280) decreased expression of $c z o A:: l a c Z$ compared to $S 44$ with addition of cefalexin and cefazolin (Figure 6C), possibly because transcription level of $c z o R$ was decreased in iscR-280 (Figure 6A). However, in $\triangle c z o R, \beta$-gal activity of CzoA::LacZ was almost non-existent, even at higher concentrations of cefalexin and cefazolin $(50-100 \mu \mathrm{g} / \mathrm{ml})$ or using different induction times (data not shown), indicating that $c z o R$ is essential for $c z o A$ expression. Although iscR expression was also induced by cefalexin and cefazolin in $\Delta c z o R$, IscR could not directly regulate $c z o A$ expression without CzoR. Higher $\beta$-gal activities in iscR-280C and $\triangle c z o R-C$ compared to S44 may be attributable to a multicopy-based complementation used for both iscR and $c z o R$. These results suggest that IscR may positively regulate $c z o R$ expression of and affect $c z o A$ expression, which provided a link between IscR and $\beta$-lactam susceptibility regulation.

\section{DISCUSSION}

CzoA, newly identified in C. testosteroni S44, hydrolyzed some penicillins and cephalosporins, and was inhibited by tazobactam or clavulanic acid (Tables 1, 2). Substrate and inhibition profiles are similar to those of several reported group $2 \mathrm{~b}$ Class A $\beta$-lactamases (see review of Bush and Jacoby, 2010). Surprisingly, unlike most class A $\beta$-lactamases, kinetic parameters of purified CzoA $\beta$-lactamase showed that CzoA had hydrolysis activities against ceftriaxone and cefepime (Table 2). $k_{\text {cat }}$ values of ceftriaxone $\left(3 \pm 0.05 \mathrm{~s}^{-1}\right)$ and cefepime $\left(2 \pm 0.6 \mathrm{~s}^{-1}\right)$ and low $K_{\mathrm{m}}$ values $(0.24 \pm 0.007 \mathrm{mM}, 0.30 \pm 0.02 \mathrm{mM})$ lead to relatively high $k_{\text {cat }} / K_{\mathrm{m}}$ values (Table 2). Fold change of imipenem MICs between the strains E. coli DH5 $\alpha$ (pCT-Zori::czoA) and E. coli $\mathrm{DH} 5 \alpha$ (pCT-Zori) indicated CzoA showed resistance to imipenem, which is similar to carbapenem-hydrolyzing serine class A $\beta$-lactamases NmcA of E. cloacae NOR-1 and Sme-1 of S. marcescens S6 (Naas and Nordmann, 1994; Naas et al., 1995). However, CzoA did not confer resistance to meropenem in E. coli. Class B and Class D $\beta$-lactamases, existed in S44, may 
have overlapping functions compared with Class A $\beta$-lactamase, such as CzoA, since Class B and Class D $\beta$-lactamases showed hydrolysis activities to most $\beta$-lactams, including carbapenems, and cloxacillin/oxacillin/carbapenems, respectively (Bush and Jacoby, 2010).

In opposite orientation from the PczoA, a LysR-type transcriptional regulatory protein CzoR was identified (Figure 1). As is often the case for other LysR-regulated genes, genes encoding Class A $\beta$-lactamase and regulator were adjacent and opposite to one another, with overlapping and divergent promoters, which may provide tighter control of gene overexpression and prevent an inadvertent gene activation (Naas and Nordmann, 1994).

We observed that $c z o A$ expression was induced by $11 \beta$-lactams and $c z o R$ was induced by $9 \beta$-lactams and constitutively transcribed with or without cefuroxime and cefoxitin (Figures 2A,B). Such results are somehow in agreement with previous studies. For example, $c d i A R$ operon encoding for Class A $\beta$-lactamase biosynthesis were also inducible by $\beta$-lactams in E. coli strains (Jones and Bennett, 1995). As for SmeR, $\beta$-lactams did not affect its expression (Naas et al., 1995). While in C. gillenii, no LysR-type regulatory gene was found upstream of the $b l a_{G I L-1}$ gene, which fits non-inducibility of $\beta$-lactamase expression (Naas et al., 2007). Although some $\beta$-lactams can induce AmpC, these $\beta$-lactams were not direct bind AmpR (Jones and Bennett, 1995).

Even though CzoR acting as a positive regulator for CzoA is similar to previous reported LysR-type regulators, such as CdiR, HugR, NmcR, PenR, SedR, and SmeR (Datz et al., 1994; Naas and Nordmann, 1994; Jones and Bennett, 1995; Naas et al., 1995; Petrella et al., 2001; Liassine et al., 2002; Poirel et al., 2009; Guérin et al., 2015), our results discovered a novel LysR-type (CzoR)-binding motif $\left(5^{\prime}\right.$-TCTCAATCAAGATAAAA- $\left.3^{\prime}\right)$ in C. testosteroni S44 (Figure 4). Such motif is different from the reported AmpRbinding sites in C. freundii, E. cloacae NOR-1, S. marcescens S6, and P. aeruginosa (Lindquist et al., 1989; Naas and Nordmann, 1994; Naas et al., 1995; Balasubramanian et al., 2012).

In addition to the CzoR-binding motif, we also found a putative IscR-binding motif in the $c z o R-c z o A$ intergenic region (Figure 5). Previous studies have shown that $I s c R$ is a global regulator involved in regulation of various physiological processes during growth and stress responses (Daung-nkern et al., 2010; Zheng et al., 2014; Liu H.L. et al., 2015), but little is known about the role of IscR in antibiotic susceptibility regulation interacting with $\beta$-lactamase. This study demonstrated that IscR indirectly influenced $c z o A$ expression through $c z o R$ regulation based on following observations (Figures 2, 3, 5, 6): (i) IscR/CzoR/CzoA was induced by cefalexin and cefazolin, and IscR could directly bind to the $c z o R-$ $c z o A$ promoter; (ii) iscR deletion decreased transcription level of $c z o R$ and $c z o A$; (iii) $c z o R$ deletion had no effect on iscR transcription, although $c z o A$ expression was completely inhibited; and (iv) susceptibility to cefalexin and cefazolin was increased in $\triangle i s c R$ and further increased in $\triangle c z o R$. CzoR, therefore, acted as a positive regulator for CzoA $\beta$-lactamase biosynthesis and IscR positive regulated $c z o R$ expression.

It has been shown that Fe-S cluster biosynthesis may also be involved in antibiotic susceptibility (Daung-nkern et al., 2010; Liu et al., 2010). Disruption of Fe-S cluster results in $\mathrm{Fe}(\mathrm{II})$-mediated Fenton reactions and enhances oxidative stress. Our previous work showed that deletion of iscR significantly decreased cellular $\gamma$-glutamylcysteine ligase $(\gamma$-GCL) activity and glutathione (GSH) content (Liu H.L. et al., 2015), which play important roles in $\mathrm{Fe}-\mathrm{S}$ cluster formation and $\mathrm{H}_{2} \mathrm{O}_{2}$ consumption, respectively (Qi et al., 2012; Wang et al., 2012). To guard against oxidative stress resulting from bactericidal agents, such as $\beta$-lactams, IscR may respond to $\beta$-lactaminduced stress, such as cefalexin and cefazolin, faster than CzoR.

In summary, our results reveal a novel mechanism in which CzoR positively regulates $c z o A$, and $\mathrm{IscR}$ enhances the regulation by $\mathrm{CzoR}$. Since IscR is a global regulator for cellular oxidative stress response, it is reasonable that IscR regulates expression of some $\beta$-lactamases, such as CzoA expression which is related to bacterial cell wall stress remission. Our study provides a new insight into the regulatory mechanism of class A $\beta$-lactamases and demonstrates, for the first time, that IscR is involved in antibiotic susceptibility via the regulation of czoR-czoA.

\section{AUTHOR CONTRIBUTIONS}

WZ and HL designed and performed the experiments and wrote the manuscript. JL wrote and revised the draft of the manuscript. LC participated in the experiments. GW designed the study and revised the draft of the manuscript. All authors read and approved the final manuscript.

\section{FUNDING}

This study was supported by the National Natural Science Foundation of China (31470226) for GW, the Research Fund of Tianjin Key Laboratory of Aquatic Science and Technology (Grant No. TJKLAST-ZD-2016-04) for HL, the National Natural Science Foundation of China (31500085) for HL, and the Open Project of State Key Laboratory of Agricultural Microbiology (AMLKF201503) in Huazhong Agricultural University for HL.

\section{SUPPLEMENTARY MATERIAL}

The Supplementary Material for this article can be found online at: https://www.frontiersin.org/articles/10.3389/fmicb. 2017.02573/full\#supplementary-material 


\section{REFERENCES}

Bailey, T. L., and Elkan, C. (1994). Fitting a mixture model by expectation maximization to discover motifs in biopolymers. Proc. Int. Conf. Intell. Syst. Mol. Biol. 2, 28-36.

Balasubramanian, D., Schneper, L., Merighi, M., Smith, R., Narasimhan, G., Lory, S., et al. (2012). The regulatory repertoire of Pseudomonas aeruginosa AmpC $\beta$-lactamase regulator AmpR includes virulence genes. PLOS ONE 7:e34067. doi: 10.1371/journal.pone.0034067

Bush, K. (2013). Proliferation and significance of clinically relevant $\beta$-lactamases. Ann. N. Y. Acad. Sci. 1277, 84-90. doi: 10.1111/nyas.12023

Bush, K., and Bradford, P. A. (2016). $\beta$-Lactams and $\beta$-lactamase inhibitors: an overview. Cold Spring Harb. Perspect. Med. 6:a025247. doi: 10.1101/cshperspect. a025247

Bush, K., and Jacoby, G. A. (2010). Updated functional classification of $\beta$ lactamases. Antimicrob. Agents Chemother. 54, 969-976. doi: 10.1128/AAC. 01009-09

Bush, K., Jacoby, G. A., and Medeiros A. A. (1995). A functional classification scheme for $\beta$-lactamases and its correlation with molecular structure. Antimicrob. Agents Chemother. 39, 1211-1233. doi: 10.1128/AAC.39.6.1211

Bush, K., and Sykes, R. B. (1986). Methodology for the study of $\beta$-lactamases. Antimicrob. Agents Chemother. 30, 6-10. doi: 10.1128/AAC.30.1.6

Caille, O., Zincke, D., Merighi, M., Balasubramanianb, D., Kumaria, H., Kong, K. F., et al. (2014). Structural and functional characterization of Pseudomonas aeruginosa global regulator AmpR. J. Bacteriol. 196, 3890-3902. doi: 10.1128/ JB.01997- 14

Chen, F., Cao, Y. J., Wei, S., Li, Y. Z., Li, X., Wang, Q., et al. (2015). Regulation of arsenite oxidation by the phosphate two-component system PhoBR in Halomonas sp. HAL1. Front. Microbiol. 6:923. doi: 10.3389/fmicb.2015. 00923

Clinical and Laboratory Standards Institute (2014). Performance Standards for Antimicrobial Susceptibility Testing; 24th Informational Supplement. CLSI Document M100-S24. Wayne, PA: Clinical and Laboratory Standards Institute.

Datz, M., Joris, B., Azab, E. A., Galleni, M., Beeumen, J., Frère, J. M., et al. (1994). A common system controls the induction of very different genes. The class-A $\beta$ lactamase of Proteus vulgaris and the enterobacterial class-C $\beta$-lactamase. Eur. J. Biochem. 226, 149-157. doi: 10.1111/j.1432-1033.1994.tb20036.x

Daung-nkern, J., Vattanaviboon, P., and Mongkolsuk, S. (2010). Inactivation of $n f u A$ enhances susceptibility of Pseudomonas aeruginosa to fluoroquinolone antibiotics. J. Antimicrob. Chemother. 65, 1831-1832. doi: 10.1093/jac/dkq194

Duran, A., Abacilar, A. F., Uyar, I. S., Akpinar, M. B., Sahin, V., Okur, F. F., et al. (2015). Comamonas testosteroni endocarditis in Turkey: a case report and review of the literature. Sifa Med. J. 2, 44-47. doi: 10.4103/2148-7731.152117

Dwyer, D. J., Kohanski, M. A., and Collins, J. J. (2009). Role of reactive oxygen species in antibiotic action and Resistance. Curr. Opin. Microbiol. 12, 482-489. doi: 10.1016/j.mib.2009.06.018

Giel, J. L., Nesbit, A. D., Mettert, E. L., Fleischhacker, A. S., Wanta, B. T., and Kiley, P. J. (2013). Regulation of iron-sulphur cluster homeostasis through transcriptional control of the Isc pathway by [2Fe-2S]-IscR in Escherichia coli. Mol. Microbiol. 87, 478-492. doi: 10.1111/mmi.12052

Giel, J. L., Rodionov, D., Liu, M., Blattner, F. R., and Kiley, P. J. (2006). IscRdependent gene expression links iron-sulphur cluster assembly to the control of $\mathrm{O}_{2}$-regulated genes in Escherichia coli. Mol. Microbiol. 60, 1058-1075. doi: $10.1111 / \mathrm{j} .1365-2958.2006 .05160 . \mathrm{x}$

Girlich, D., Leclercq, R., Naas, T., and Nordmann, P. (2007). Molecular and biochemical characterization of the chromosome-encoded class A $\beta$-lactamase BCL-1 from Bacillus clausii. Antimicrob. Agents Chemother. 51, 4009-4014. doi: 10.1128/AAC.00537-07

Giwercman, B., Meyer, C., Lambert, P. A., Reinert, C., and Hoiby, N. (1992). High-level $\beta$-lactamase activity in sputum samples from cystic fibrosis patients during antipseudomonal treatment. Antimicrob. Agents Chemother. 36, 71-76. doi: 10.1128/AAC.36.1.71

Guan, X., Chen, P., Xu, Q., Qian, L., Huang, J., and Lin, B. (2017). Expression, purification and molecular characterization of a novel endoglucanase protein from Bacillus subtilis SB13. Protein Expr. Purif. 134, 125-131. doi: 10.1016/j. pep.2017.04.009

Guérin, F., Isnard, C., Cattoir, V., and Giard, J. C. (2015). Complex regulation pathways of AmpC-mediated $\beta$-lactam susceptibility in Enterobacter cloacae complex. Antimicrob. Agents Chemother. 59, 7753-7761. doi: 10.1128/AAC. 01729-15

Haines, S., Arnaud-Barbe, N., Poncet, D., Reverchon, S., Wawrzyniak, J., Nasser, W., et al. (2015). IscR regulates synthesis of colonization factor antigen I fimbriae in response to iron starvation in enterotoxigenic Escherichia coli. J. Bacteriol. 197, 2896-2907. doi: 10.1128/JB.00214-15

Jones, M. E., and Bennett, P. M. (1995). Inducible expression of the chromosomal $c$ diA from Citrobacter diversus NF85, encoding an ambler class A $\beta$-lactamase, is under similar genetic control to the chromosomal $a m p C$, encoding an ambler class C enzyme, from Citrobacter freundii OS60. Microb. Drug Resist. 1, 285-291. doi: 10.1089/mdr.1995.1.285

Jorgensen, J. H., Turnidge, J. D., Washington, J. A., Murray, P. R., Pfaller, M. A., and Tenover, F. C. (1999). "Antibacterial susceptibility tests: dilution and disk diffusion methods," in Manual of Clinical Microbiology, 7th Edn, eds P. R. Murray, E. J. Baron, M. A. Pfaller, F. C. Tenover, and R. H. Yolken (Washington, DC: ASM Press), 1526-1543.

Lamoureaux, T. L., Vakulenko, V., Toth, M., Frase, H., and Vakulenko, S. B. (2013). A novel extended-spectrum $\beta$-lactamase, sgm-1, from an environmental isolate of Sphingobium sp. Antimicrob. Agents Chemother. 57, 3783-3788. doi: 10.1128/AAC.00808-13

Liassine, N., Madec, S., Ninet, B., Metral, C., Fouchereau-Peron, M., Labia, R., et al. (2002). Postneurosurgical meningitis due to Proteus penneri with selection of a ceftriaxone-resistant isolate: analysis of chromosomal class A $\beta$ lactamase HugA and its LysR-type regulatory protein HugR. Antimicrob. Agents Chemother. 46, 216-219. doi: 10.1128/AAC.46.1.216-219.2002

Liu, A., Tran, L., Becket, E., Lee, K., Chinn, L., Park, E., et al. (2010). Antibiotic sensitivity profiles determined with an Escherichia coli gene knockout collection: generating an antibiotic bar code. Antimicrob. Agents Chemother. 54, 1393-1403. doi: 10.1128/AAC.00906-09

Liu, H. L., Zhuang, W. P., Zhang, S. Z., Rensing, C., Huang, J., Jie, L., et al. (2015). Global regulator IscR positively contributes to antimonite resistance and oxidation in Comamonas testosteroni S44. Front. Mol. Biosci. 2:70. doi: 10.3389/fmolb.2015.00070

Liu, L., Zhu, W., Cao, Z., Xu, B., Wang, G., and Luo, M. (2015). High correlation between genotypes and phenotypes of environmental bacteria Comamonas testosteroni strains. BMC Genomics 16:110. doi: 10.1186/s12864-015-1314-x

Lindquist, S., Lindberg, F., and Normark, S. (1989). Binding of the Citrobacter freundii AmpR regulator to a single DNA site provides both autoregulation and activation of the inducible $a m p C \beta$-lactamase gene. J. Bacteriol. 171, 3746-3753. doi: 10.1128/jb.171.7.3746-3753.1989

Miller, V. L., and Mekalanos, J. J. (1988). A novel suicide vector and its use in construction of insertion mutations: osmoregulation of outer membrane proteins and virulence determinants in Vibrio cholerae requires toxR. J. Bacteriol. 170, 2575-2583. doi: 10.1128/jb.170.6.2575-2583.1988

Naas, T., Aubert, D., Ozcan, A., and Nordmann, P. (2007). Chromosome-encoded narrow-spectrum Ambler class A $\beta$-lactamase GIL-1 from Citrobacter gillenii. Antimicrob. Agents Chemother. 51, 1365-1372. doi: 10.1128/AAC.01152-06

Naas, T., Livermore, D. M., and Nordmann, P. (1995). Characterization of a LysR family protein, SmeR from Serratia marcescens S6, its effect on expression of the carbapenem-hydrolyzing $\beta$-lactamase Sme-1, and comparison of this regulator with other $\beta$-lactamase regulators. Antimicrob. Agents Chemother. 39, 629-637. doi: 10.1128/AAC.39.3.629

Naas, T., and Nordmann, P. (1994). Analysis of a carbapenem-hydrolyzing class A $\beta$-lactamase from Enterobacter cloacae and of its LysR-type regulatory protein. Proc. Natl. Acad. Sci. U.S.A. 91, 7693-7697. doi: 10.1073/pnas.91.16.7693

Novichkov, P. S., Kazakov, A. E., Ravcheev, D. A., Leyn, S. A., Kovaleva, G. Y., Sutormin, R. A., et al. (2013). RegPrecise 3.0 - a resource for genome-scale exploration of transcriptional regulation in bacteria. BMC Genomics 14:745. doi: 10.1186/1471-2164-14-745

Parolin, M., Baraldi, M., Valentini, E., Murer, L., and Vidal, E. (2016). Comamonas testosteroni-associated peritonitis in a pediatric peritoneal dialysis patient. World J. Nephrol. 5, 220-223. doi: 10.5527/wjn.v5.i2.220

Petrella, S., Clermont, D., Casin, I., Jarlier, V., and Sougakoff, W. (2001). Novel class A $\beta$-lactamase Sed-1 from Citrobacter sedlakii: genetic diversity of $\beta$-lactamases within the Citrobacter genus. Antimicrob. Agents Chemother. 45, 2287-2298. doi: 10.1128/AAC.45.8.2287-2298.2001

Pfaffl, M. W. (2001). A new mathematical model for relative quantification in real-time RT-PCR. Nucleic Acids Res. 29:e45. doi: 10.1093/nar/29.9.e45 
Poirel, L., Rodriguez-Martinez, J. M., Plesiat, P., and Nordmann, P. (2009). Naturally occurring class A $\beta$-lactamases from the Burkholderia cepacia complex. Antimicrob. Agents Chemother. 53, 876-882. doi: 10.1128/AAC. 00946-08

Philippon, A., Slama, P., Dény, P., and Labia, R. (2016). A structure-based classification of class A $\beta$-lactamases, a broadly diverse family of enzymes. Clin. Microbiol. Rev. 29, 29-57. doi: 10.1128/CMR.00019-15

Qi, W., Li, J., Chain, C. Y., Pasquevich, G. A., Pasquevich, A. F., and Cowan, J. A. (2012). Glutathione complexed Fe-S centers. J. Am. Chem. Soc. 134, 10745-10748. doi: 10.1021/ja302186j

Schwartz, C. J., Giel, J. L., Patschkowski, T., Luther, C., Ruzicka, F. J., Beinert, H., et al. (2001). IscR, a Fe-S cluster-containing transcription factor, represses expression of Escherichia coli genes encoding Fe-S cluster assembly proteins. Proc. Natl. Acad. Sci. U.S.A. 98, 14895-14900. doi: 10.1073/pnas.2515 50898

Shi, K., Fan, X., Qiao, Z., Han, Y., McDermott, T. R., Wang, Q., et al. (2017). Arsenite oxidation regulator AioR regulates bacterial chemotaxis towards arsenite in Agrobacterium tumefaciens GW4. Sci. Rep. 7:43252. doi: 10.1038/srep 43252

Simon, R., Priefer, U., and Pühler, A. (1983). A broad host range mobilization system for in vivo genetic engineering transposon mutagenesis in gram negative bacteria. Nat. Biotechnol. 1, 784-791. doi: 10.1038/nbt1183-784

Solovyev, V., and Salamov, A. (2011). "Automatic annotation of microbial genomes and metagenomic sequences," in Metagenomics and its Applications in Agriculture, Biomedicine and Environmental Studies, ed. R. W. Li (Hauppauge, NY: Nova Science Publishers), 61-78.

Trépanier, S., Prince, A., and Huletsky, A. (1997). Characterization of the penA and penR genes of Burkholderia cepacia 249 which encode the chromosomal class
A penicillinase and its LysR-type transcriptional regulator. Antimicrob. Agents Chemother. 41, 2399-2405.

Walsh, T. R., Toleman, M. A., Poirel, L., and Nordmann, P. (2005). Metallo$\beta$-lactamases: the quiet before the storm? Clin. Microbiol. Rev. 18, 306-325. doi: 10.1128/CMR.18.2.306-325.2005

Wang, L., Ouyang, B., Li, Y., Feng, Y., Jacquot, J. P., Rouhier, N., et al. (2012). Glutathione regulates the transfer of iron-sulfur cluster from monothiol and dithiol glutaredoxins to apo ferredoxin. Protein Cell 3, 714-721. doi: 10.1007/ s13238-012-2051-4

Xiong, J. B., Li, D. M., Li, H., He, M. Y., Miller, S. J., Yu, L., et al. (2011). Genome analysis and characterization of zinc efflux systems of a highly zinc resistant bacterium, Comamonas testosteroni S44. Res. Microbiol. 162, 671-679. doi: 10.1016/j.resmic.2011.06.002

Zheng, S. X., Su, J., Wang, L., Yao, R., Wang, D., Deng, Y., et al. (2014). Selenite reduction by the obligate aerobic bacterium Comamonas testosteroni S44 isolated from a metal-contaminated soil. BMC Microbiol. 14:204. doi: 10.1186/s12866-014-0204-8

Conflict of Interest Statement: The authors declare that the research was conducted in the absence of any commercial or financial relationships that could be construed as a potential conflict of interest.

Copyright (c) 2017 Zhuang, Liu, Li, Chen and Wang. This is an open-access article distributed under the terms of the Creative Commons Attribution License (CC BY). The use, distribution or reproduction in other forums is permitted, provided the original author(s) or licensor are credited and that the original publication in this journal is cited, in accordance with accepted academic practice. No use, distribution or reproduction is permitted which does not comply with these terms. 